\title{
Painless Type B Aortic Dissection Insights From the International Registry of Acute Aortic Dissection
}

\author{
Jip L. Tolenaar, MD ${ }^{1}$, Stuart J. Hutchison, $\mathrm{MD}^{2}$, Dan Montgomery, MS ${ }^{3}$, Patrick O'Gara, MD ${ }^{4}$, \\ Rosella Fattori, $\mathrm{MD}^{5}$, Reed E. Pyeritz, MD, PhD ${ }^{6}$, Linda Pape, $\mathrm{MD}^{7}$, Toru Suzuki, MD ${ }^{8}$, \\ Arturo Evangelista, $\mathrm{MD}^{9}$, Frans L. Moll, MD, $\mathrm{PhD}^{10}$, Vincenzo Rampoldi, $\mathrm{MD}^{1}$, \\ Eric M. Isselbacher, $M D^{11}$, Cristoph A. Nienaber, MD, FACC ${ }^{12}$, Kim A. Eagle, MD, FACC ${ }^{3}$, \\ Santi Trimarchi, MD, $\mathrm{PhD}^{1 *}$
}

\begin{abstract}
${ }^{1}$ Department of Cardiovascular Surgery, Policlinico San Donato IRCCS, Milan, Italy; ${ }^{2}$ St. Michael's Hospital, Toronto, Ontario, Canada; ${ }^{3}$ University of Michigan Health System, Ann Arbor, Michigan; ${ }^{4}$ Brigham and Women's Hospital, Boston, Massachusetts; ${ }^{5} \mathrm{~S}$. OrsolaMalpighi Hospital, Bologna, Italy; ${ }^{6}$ Perelman School of Medicine, University of Pennsylvania, Philadelphia, Pennsylvania; ${ }^{7}$ University of Massachusetts Hospital, Worcester, Massachusetts; ${ }^{8}$ Department of Cardiology, University of Tokyo, Tokyo, Japan; ${ }^{9}$ Hospital General Universitari Vall d'Hebron, Barcelona, Spain; ${ }^{10}$ University Medical Center Utrecht, Utrecht, The Netherlands; ${ }^{11}$ Massachusetts General Hospital, Boston, Massachusetts; ${ }^{12}$ Thoracic Aortic Center, University of Rostock, Rostock, Germany
\end{abstract}

\begin{abstract}
Introduction: The classical presentation of a patient with Type $B$ acute aortic dissection (TBAAD) is characterized by severe chest, back, or abdominal pain, ripping or tearing in nature. However, some patients present with painless acute aortic dissection, which can lead to a delay in diagnosis and treatment. We utilized the International Registry on Acute Aortic Dissections (IRAD) database to study these patients. Methods: We analyzed 43 painless TBAAD patients enrolled in the database between January 1996 and July 2012. The differences in presentation, diagnostics, management, and outcome were compared with patients presenting with painful TBAAD. Results: Among the 1162 TBAAD patients enrolled in IRAD, 43 patients presented with painless TBAAD $(3.7 \%)$. The mean age of patients with painless TBAAD was significantly higher than normal TBAAD patients (69.2 versus 63.3 years, $P=0.020$ ). The presence of atherosclerosis $(46.4 \%$ versus $30.1 \%$, $P=0.022)$, diabetes $(17.9 \%$ versus $7.5 \% ; P=0.018)$, and other aortic diseases $(8.6 \%$ versus $2.3 \%, P=$ $0.051)$, such as prior aortic aneurysm ( $31 \%$ versus $18.8 \% P=0.049$ ) was more common in these pa-
\end{abstract}

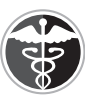

Fax +1 2037853346

E-Mail: aorta@scienceinternational.org

http://aorta.scienceinternational.org (c) 2013 Aorta.

Published by Science International Corp. ISSN 2325-4637

Accessible online at:

http://aorta.scienceinternational.org tients. Median delay time between presentation and diagnosis was longer in painless patients (median 34.0 versus 19.0 hours; $P=0.006$ ). Dissection of iatrogenic origin ( $19.5 \%$ versus $1.3 \% ; P<0.001)$ was significantly more frequent in the painless group. The in-hospital mortality was $18.6 \%$ in the painless group, compared with an in-hospital mortality of $9.9 \%$ in the control group $(P=0.063)$. Conclusion: Painless TBAAD is a relatively rare presentation $(3.7 \%)$ of aortic dissection, and is often associated with a history of atherosclerosis, diabetes, prior aortic disease including aortic aneurysm, and an iatrogenic origin. We observed a trend for increased in-hospital mortality in painless TBAAD patients, which may be the result of a delay in diagnosis and management. Therefore, physicians should be aware of this relative rare presentation of TBAAD.

Copyright ๑ 2013 Science International Corp.

\section{Key Words}

Aortic dissection - Painless

${ }^{*}$ Corresponding author:

Santi Trimarchi, MD, PhD

Department of Cardiovascular Surgery

Policlinico San Donato IRCCS

University of Milano

Thoracic Aorta Research Center

Piazza Malan 2

20097 San Donato Milanese MI, Italy

Tel: +39 02 52774339, Fax: +3902 52774415, E-Mail: santi.trimarchi@unimi.it 
Table 1. Demographics and Patient History

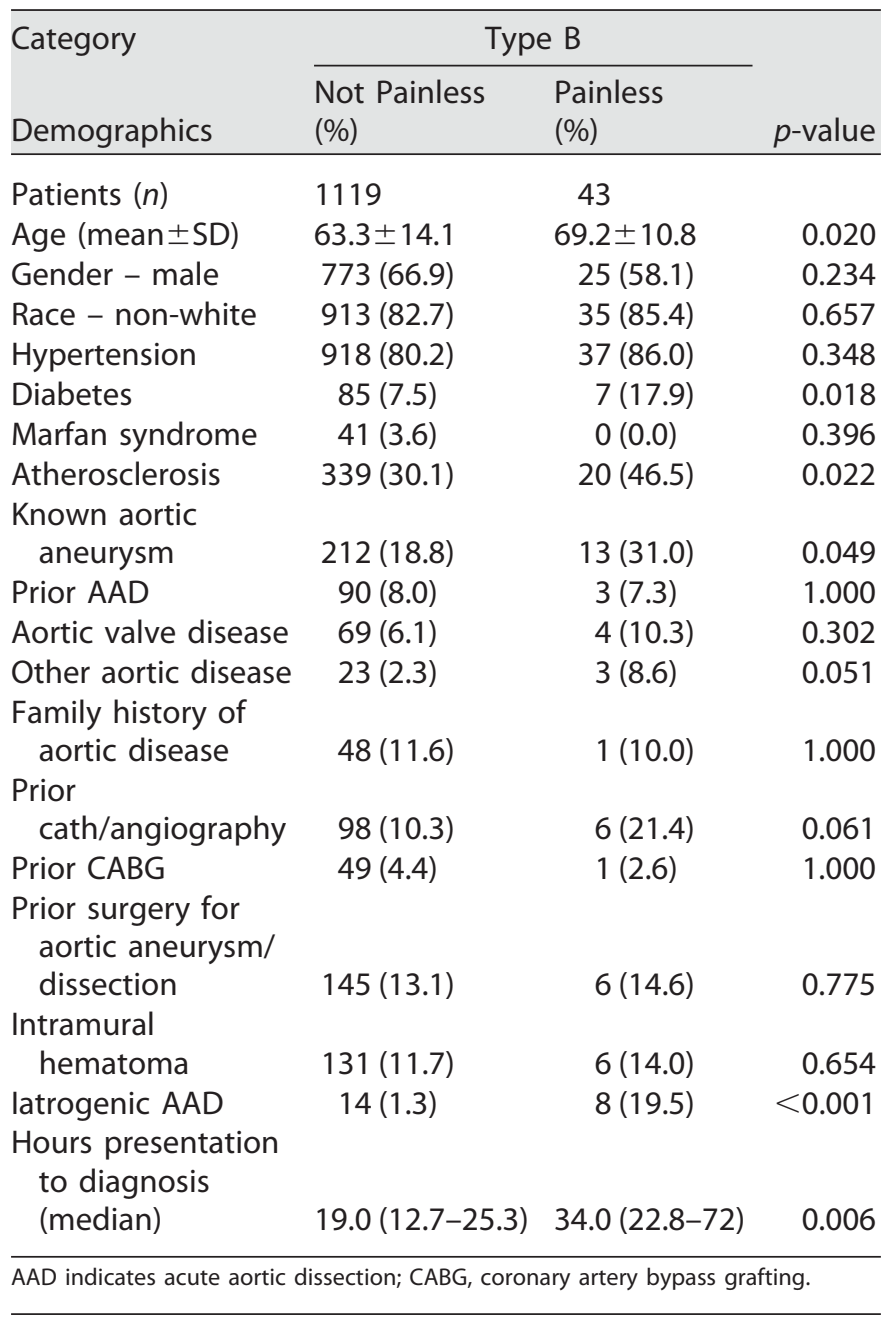

\section{Introduction}

The classical presentation of a patient with acute aortic dissection (AAD) is characterized by severe chest, back, or abdominal pain. However, previous reports showed that between 5 and $17 \%$ of all dissection patients present with painless acute aortic dissections $[1,2]$. As expected, atypical presentation can lead to a delay in diagnosis, which is associated with higher mortality $[3,4]$. Painless Type B acute aortic dissection (TBAAD) does not mean that these patients have uncomplicated dissections, as they still can develop malperfusion and aortic rupture [1,2]. Immediate adequate medical treatment is essential and has to include optimal blood pressure control in order to reduce shear stress and limit the propagation of the dissection. Therefore, it is important to recognize these patients at the earliest
Table 2. Presenting Symptoms/Signs of Aortic Dissection

\begin{tabular}{|c|c|c|c|}
\hline \multirow[b]{2}{*}{ Category } & \multicolumn{2}{|c|}{ Type B } & \multirow[b]{2}{*}{$p$-value } \\
\hline & $\begin{array}{l}\text { Not Painless } \\
(\%)\end{array}$ & $\begin{array}{l}\text { Painless } \\
(\%)\end{array}$ & \\
\hline Presenting hypertensive & $763(68.8)$ & $17(45.9)$ & 0.003 \\
\hline $\begin{array}{l}\text { Presenting hypotensive } \\
\text { Mean systolic blood }\end{array}$ & $80(7.3)$ & $4(10.0)$ & 0.532 \\
\hline $\begin{array}{l}\text { pressure } \\
\text { Mean systolic blood }\end{array}$ & 166.8 & 147.2 & 0.003 \\
\hline pressure & 91.44 & 85.0 & 0.095 \\
\hline $\begin{array}{l}\text { Presented with pulse } \\
\text { deficits }\end{array}$ & $173(18.6)$ & $2(8.3)$ & 0.286 \\
\hline Shock & $11(1.0)$ & $1(2.7)$ & 0.327 \\
\hline Syncope & $28(2.5)$ & $4(10.3)$ & 0.020 \\
\hline $\begin{array}{l}\text { Cerebrovascular } \\
\text { accident }\end{array}$ & $14(1.3)$ & $2(5.1)$ & 0.100 \\
\hline $\begin{array}{l}\text { Ischemic peripheral } \\
\text { neuropathy }\end{array}$ & $31(2.8)$ & $0(0)$ & 0.622 \\
\hline Spinal cord ischemia & $31(2.8)$ & $0(0)$ & 0.622 \\
\hline Limb ischemia & $101(9.3)$ & $0(0)$ & 0.043 \\
\hline Acute renal failure & $161(14.8)$ & $8(20.0)$ & 0.364 \\
\hline
\end{tabular}

possible stage. The aim of the current study was to assess the clinical characteristics, diagnostics, treatment, and outcomes of patients with painless TBAAD.

\section{Methods}

\section{Patient Selection}

The International Registry of Acute Aortic Dissection (IRAD) is an ongoing multinational registry designed to provide a representative population of patients with acute aortic dissection. The rationale, design, and methods of IRAD have been previously published [5]. The diagnosis of TBAAD was based on clinical symptoms, diagnostic imaging, direct visualization during surgery, and/or postmortem examination. Patients were enrolled at diagnosis or retrospectively. We analyzed all TBAAD patients enrolled in IRAD from January 1996 to July 2012 and selected those patients presenting without any pain symptoms. Demographics, medical history, presenting symptoms, management, and outcomes were compared between patients presenting with and without pain.

\section{Statistical Analysis}

Categorical variables were compared for both groups utilizing the chi-squared tests and Fisher's exact tests. Student's t-test was used to analyze continuous variables and the nonparametric test of medians to analyze non-normally distributed variables. A $p$-value $<0.05$ was considered significant. Kaplan-Meier survival curves were plotted to estimate survival. Data analysis was performed with the use of SPSS statistical analysis software (SPSS Inc, Chicago, III). 
Table 3. Imaging

\begin{tabular}{|c|c|c|c|}
\hline \multirow[b]{2}{*}{ Category } & \multicolumn{2}{|c|}{ Type B } & \multirow[b]{2}{*}{$p$-value } \\
\hline & $\begin{array}{l}\text { Not Painless } \\
(\%)\end{array}$ & $\begin{array}{l}\text { Painless } \\
(\%)\end{array}$ & \\
\hline CXR done & $1002(86.7)$ & $37(86.0)$ & 0.905 \\
\hline CXR normal & $275(28.1)$ & $8(21.6)$ & 0.389 \\
\hline $\begin{array}{l}\text { CXR showed } \\
\text { abnormal } \\
\text { aortic contour }\end{array}$ & 397 (43.9) & $16(47.1)$ & 0.713 \\
\hline $\begin{array}{l}\text { CXR showed } \\
\text { abnormal }\end{array}$ & & & \\
\hline cardiac contour & $141(15.8)$ & $2(6.2)$ & 0.211 \\
\hline ECG done & $1087(94.0)$ & $36(83.7)$ & 0.006 \\
\hline ECG normal & 409 (38.2) & $10(28.6)$ & 0.250 \\
\hline TEE done & $574(50.4)$ & $20(47.6)$ & 0.724 \\
\hline CT done & $1110(96.2)$ & $34(82.9)$ & $<0.001$ \\
\hline CT Normal & $6(0.6)$ & $1(3.2)$ & 0.184 \\
\hline Angiography & 207 (18.2) & $9(24.3)$ & 0.345 \\
\hline MRI done & $185(16.7)$ & $10(27.8)$ & 0.081 \\
\hline $\begin{array}{l}\text { Periaortic } \\
\text { hematoma } \\
\text { identified on } \\
\text { any imaging }\end{array}$ & & & \\
\hline study & $150(14.5)$ & $6(16.7)$ & 0.718 \\
\hline $\begin{array}{l}\text { Most proximal } \\
\text { extension: }\end{array}$ & & & \\
\hline Aortic arch & $263(22.8)$ & $7(16.3)$ & 0.318 \\
\hline $\begin{array}{l}\text { Left subclavian } \\
\text { artery }\end{array}$ & 577 (49.9) & $19(44.2)$ & 0.461 \\
\hline Descending & $280(24.2)$ & $13(30.2)$ & 0.368 \\
\hline $\begin{array}{l}\text { Largest diameter of } \\
\text { descending } \\
\text { aorta (median) }\end{array}$ & $4.0(3.5-5.0)$ & $3.6(3.0-4.7)$ & 0.137 \\
\hline
\end{tabular}

\section{Results}

Among the 1162 TBAAD patients enrolled in IRAD, 43 patients presented with painless TBAAD (3.7\%). The mean age of patients with painless TBAAD was significantly higher than normal TBAAD patients (69.2 versus $63.3 \mathrm{y}$; $p$-value $=0.020$, Tables $1-3$ ). Painless patients presented more often with a history of diabetes, (17.9\% versus $7.5 \% ; P=0.018)$, atherosclerosis $(46.4 \%$ versus $30.1 \%$; $P=0.022$ ), and were more often diagnosed with a known prior aortic aneurysm (31\% versus $18.8 \% ; P=0.049$ ) Painless patients presented less frequently with hypertension (45.9\% versus $68.8 \%$; $P=0.003)$ and with a lower mean systolic blood
Table 4. Management

\begin{tabular}{llrl}
\hline & \multicolumn{3}{c}{ Type B } \\
\cline { 2 - 3 } & $\begin{array}{l}\text { Not Painless } \\
\text { Category }\end{array}$ & $\begin{array}{l}\text { Painless } \\
(\%)\end{array}$ & $p$-value \\
\hline Medical management & $754(65.2)$ & $28(65.1)$ & 0.988 \\
Surgical management & $137(11.9)$ & $6(14.0)$ & 0.676 \\
Endovascular management & $251(21.7)$ & $9(20.9)$ & 0.903 \\
In-hospital mortality & $114(9.9)$ & $8(18.6)$ & 0.063 \\
$\quad$ Medical management & $57(7.8)$ & $3(10.7)$ & 0.468 \\
$\quad$ Surgery & $25(18.2)$ & $3(50.0)$ & 0.089 \\
Endovascular & $31(12.4)$ & $2(22.2)$ & 0.320 \\
\hline
\end{tabular}

pressure (mean $147.28 \mathrm{~mm} / \mathrm{Hg}$ versus $166.8 .2 \mathrm{~mm} / \mathrm{Hg}$; $P=0.003)$. Syncope was more represented in the painless group (10.3\% versus $2.5 \% ; P=0.020$ ).

\section{Diagnostics}

As might be expected, the mean time interval between admission and diagnosis of aortic dissection was 34.0 hours among painless patients, as compared to 19.0 hours in the control group $(P=0.006)$. Computed Tomographic Angiography (CTA) was more often used as the primary diagnostic modality in the painful group (96.2 versus $82.9 \%,<0.001$ ). Previous angiography was more frequently performed in the painless group and these patients also had significantly more iatrogenic dissections (19.5 versus $1.3 \% ; P<0.001$ ). The iatrogenic cause in the painless group was: Percutaneous transluminal coronary angioplasty (PCTA) in three patients $(37.5 \%)$, cardiac surgery in three patients $(37.5 \%)$, and unknown cause in two patients (25\%).

\section{Management and Outcome}

Almost two-thirds of the patients were treated medically, which did not differ between groups. (65.2 versus $65.1 \%$; $P=0.988$; Table 4.) Surgical and endovascular therapies were equally used in approximately $35 \%$ of each group. In-hospital mortality was $18.6 \%$ in the painless group, compared with an in-hospital mortality of $9.9 \%$ in the control group $(P=0.063)$. There were no statistically significant differences in complications between both groups. Kaplan-Meier survival curves did not demonstrate a significant difference in mortality during five-year follow-up ( $P=0.960$; Fig. 1$)$.

\section{Discussion}

The most common characteristic of TBAAD presentation is acute pain localized to the chest, abdomen, 


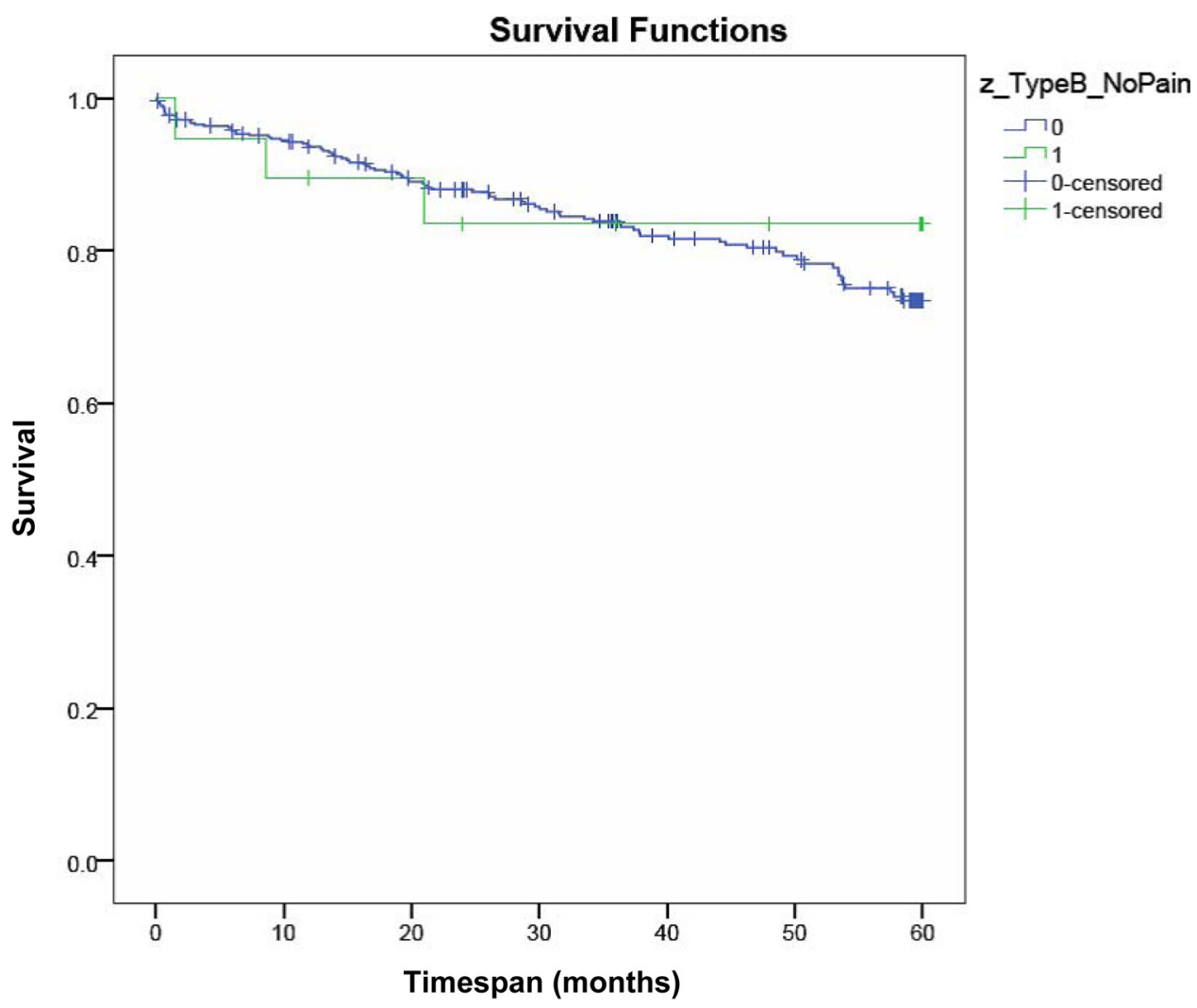

Figure 1. Kaplan Meier survival curve.

and back. Previous IRAD reports showed that $95.5 \%$ of all AAD patients presented with pain [5]. However, in rare instances the presentation of dissection can be atypical and our study showed that $3.7 \%$ of all TBAAD patients were painless, in contrast with previous experiences which reported an incidence up to $17 \%$ in AAD $[1,2]$. The lower incidence that we observed could be explained by the fact that, while this study focused only on TBAAD, previous studies focused on painless dissections in general, including a majority of patients with ascending aorta involvement (Type $A$ acute aortic dissection), which makes up for more than $75 \%$ of the patient population $[1,2]$. In addition, IRAD consists of cardiovascular referral centers, specialized in the treatment of aortic dissection, where patients are referred for surgical/endovascular treatment, whereas patients who are thought to be unfit for invasive management will not be transferred to these centers. Typically, transferred patients have more complications, resulting in a relative low incidence in the IRAD database. The true incidence in the population is probably even higher, as an atypical presentation will likely result in a higher risk of death prior to the diagnosis.
The clinical presentation of dissection patients may be diverse, and sudden collapse or an altered state of consciousness have been reported to be the presenting symptom in up to $30 \%$ of all patients [6]. This report also included TAAAD patients, which are more prone to develop complications like syncope or alteration in consciousness [7]. Painless AAD, especially concerning the ascending aorta, presents more often with neurological deficits, syncope, and disturbances in consciousness. These complications influence the perception of pain, resulting in a relative high prevalence of Type A dissection in this patient category. As expected, painless Type B dissection patients did not show this clinical pattern since involvement of the head and neck vessels did not occur.

Our study showed that TBAAD painless patients are older at presentation and more often had a history of atherosclerosis. With increasing age, the incidence of painless dissections might rise, as previously reported [1]. In that study, patients who presented at significantly older age, more frequently had a history of cerebrovascular accidents, and some patients had only atypical symptoms such as dyspnea, nausea, and 
abdominal fullness. These three atypical clinical signs were not recorded within the IRAD registry, so we can't make any comparison.

The pathological mechanism of painless TBAAD is not well understood and multiple explanations for this phenomenon have been proposed. Our study showed that painless patients present with less hypertension. Due to low blood pressure, the propagation of the dissection might develop relatively slow, thereby reducing the wall stress, which could result in reduction of pain. Alternatively, pain will act as an acute stressor, determining an increased blood pressure. Furthermore, the perception of pain can be modulated as the adventitial layer, the site for aortic innervation, is involved by the dissection or affected by previous interventions. In addition, it is thought that other pathologies, like aneurysmatic enlargement, may influence the ability to sense pain. This possibility is supported by the higher incidence of other aortic disease and previous aortic aneurysms in our study population. Most interestingly, significantly more painless patients had a dissection of iatrogenic origin. latrogenic dissections are thought to occur very rarely, with Type A dissections reported in $0.04 \%$ of the patients during percutaneous coronary interventions and in 0.12 to $0.16 \%$ after cardiac surgery procedures [8-11]. The incidence of TBAAD in these patients is thought to be even lower. During such procedures, analgesics and sedation may alter the patient's perception of pain, increasing the incidence of painless TBAAD in this subset of patients [12].

The in-hospital mortality was $18.9 \%$ in the painless group, compared with an in-hospital mortality of $10.3 \%$ in the control group $(P=0.096)$. The explanation for this trend is probably 2 -fold. First, the painless group tended to present at older age, which is a condition associated with a higher mortality [13]. Second, the extended delay to diagnosis and treatment, due to the difficulty in diagnosis, may have resulted in a higher mortality.

Although this study represents the first report focusing specifically on TBAAD with absence of pain at presentation, it has some limitations. Previous studies reported a higher incidence and registry data might not reflect the true incidence, since the centers are specialized in aortic dissection and therefore receive many referred patients. Furthermore, many patients may have died from a painless dissection before they were diagnosed and therefore are not registered.

\section{Conclusion}

Painless TBAAD is a relatively rare presentation of aortic dissection and is associated with a history of atherosclerosis, diabetes, iatrogenic origin, and aortic disease like aneurysm. We observed a trend in increased in-hospital mortality rate among painless TBAAD patients, which may be the result of a delay in diagnosis and any type of management due to the absence of classical symptoms. Therefore, physicians should be aware of this relatively rare presentation of TBAAD.

\section{Conflict of Interest}

Possible Conflict of Interest: IRAD is supported by grants from the University of Michigan Health System, Varbedian Fund for Aortic Research, Mardigian Foundation, and Gore Medical Inc (Flagstaff, Ariz).

\section{Comment on this Article or Ask a Question}

\section{References}

1. Imamura $\mathrm{H}$, Sekiguchi $\mathrm{Y}$, Iwashita T, Dohgomori $\mathrm{H}$, Mochizuki K, Aizawa K, et al. Painless acute aortic dissection. Diagnostic, prognostic and clinical implications. Circ J. 2011;75: 59-66. 10.1253/circj.CJ-10-0183

2. Park SW, Hutchison S, Mehta RH, Isselbacher EM, Cooper JV, Fang J, et al. Association of painless acute aortic dissection with increased mortality. Mayo Clin Proc. 2004;79: 1252-1257. 10.4065/79.10.1252

3. Lindsay J Jr. Aortic dissection. Heart Dis Stroke. 1992;1:69-76.

4. Mészáros I, Mórocz J, Szlávi J, Schmidt J, Tornóci L, Nagy L, et al. Epidemiology and clinicopathol- ogy of aortic dissection. Chest. 2000;117:12711278. 10.1378/chest.117.5.1271

5. Hagan PG, Nienaber CA, Isselbacher EM, Bruckman D, Karavite DJ, Russman PL, et al. The International Registry of Acute Aortic Dissection (IRAD): new insights into an old disease. JAMA. 2000;283:897-903. 10.1001/ jama.283.7.897

6. Hirata K, Wake M, Kyushima M, Takahashi T, Nakazato J, Mototake $\mathrm{H}$, et al. Electrocardiographic changes in patients with type A acute aortic dissection. Incidence, patterns and underlying mechanisms in 159 cases. J Cardiol. 2010;56:147-153. 10.1016/j.jjcc.2010.03.007
7. Nallamothu BK, Mehta RH, Saint S, Llovet A, Bossone E, Cooper JV, et al. Syncope in acute aortic dissection: diagnostic, prognostic, and clinical implications. Am J Med. 2002;113:468-471. 10.1016/S00029343(02)01254-8

8. Blakeman BM, Pifarre R, Sullivan HJ, Montoya A, Bakhos M, Grieco JG, et al. Perioperative dissection of the ascending aorta: types of repair. J Card Surg. 1988;3:9-14. 10.1111/j. 1540-8191.1988.tb00212.x

9. Pérez-Castellano N, García-Fernández MA, García EJ, Delcán JL. Dissection of the aortic sinus of Valsalva complicating coronary 
catheterization: cause, mechanism, evolution, and management. Cathet Cardiovasc Diagn. 1998;43:273-279. 10.1002/(SICI)10970304(199803)43:3<273::AID-CCD7>3.0.CO; 2-6

10. Still RJ, Hilgenberg AD, Akins CW, Daggett WM, Buckley MJ. Intraoperative aortic dissection. Ann Thorac Surg. 1992;53:374-380. 10.1016/0003-4975(92)90254-2

11. Yip $\mathrm{HK}, \mathrm{Wu} \mathrm{CJ}$, Yeh $\mathrm{KH}$, Hang $\mathrm{CL}$, Fang $\mathrm{CY}$ Hsieh KY, et al. Unusual complication of retrograde dissection to the coronary sinus of valsalva during percutaneous revascularization: a single-center experience and litera- ture review. Chest. 2001;119:493-501. 10. 1378/chest.119.2.493

12. Trimarchi S, Tsai T, Eagle KA, Isselbacher EM, Froehlich J, Cooper JV, et al. Acute abdominal aortic dissection: insight from the International Registry of Acute Aortic Dissection (IRAD). J Vasc Surg. 2007;46: 913-919. 10.1016/j.jvs.2007.07.030

13. Trimarchi S, Tolenaar JL, Tsai TT, Froehlich J, Pegorer M, Upchurch GR, et al. Influence of clinical presentation on the outcome of acute $B$ aortic dissection: evidences from IRAD. J Cardiovasc Surg. 2012;53:161-168. 10.3410/f.716447806.791852805
Cite this article as: Tolenaar $\mathrm{JL}$, Hutchison SJ, Montgomery D, O'Gara P, Fattori R, Pyeritz RE, Pape L, Suzuki T, Evangelista A, Moll FL, Rampoldi V, Isselbacher EM, Nienaber CA, Eagle KA, Trimarchi S. Painless Type B Aortic Dissection: Insights From the International Registry of Acute Aortic Dissection. Aorta 2013;1(2):96-101. DOI: http:// dx.doi.org/10.12945/j.aorta.2013.13-014 